\title{
Lower haemoglobin level and subsequent decline in kidney function in type 2 diabetic adults without clinical albuminuria
}

Received: 18 October 2005 / Accepted: 8 March 2006 / Published online: 13 April 2006

(C) Springer-Verlag 2006

\begin{abstract}
Aims/hypothesis: Anaemia has been suggested to be an independent risk factor for subsequent progression of advanced diabetic nephropathy; however, the relationship between haemoglobin levels and progression of nephropathy in patients without clinical albuminuria is unknown. Methods: We conducted this prospective hospital-based cohort study of 464 type 2 diabetic patients (149 women and 315 men, $55 \pm 13$ [mean \pm SD] years of age) with serum creatinine $<177 \mu \mathrm{mol} / \mathrm{l}(2.00 \mathrm{mg} / \mathrm{dl})$ and urinary albumin : creatinine ratio $<300 \mathrm{mg} / \mathrm{g}$ creatinine. GFR was estimated using the equation formulated by the Modification of Diet in Renal Disease Study group, refitted for Japanese individuals. Most patients had haemoglobin concentrations in the normal range $(144 \pm 15 \mathrm{~g} / \mathrm{l})$, only modest renal impairment (GFR: $74.8 \pm 14.5 \mathrm{ml} \mathrm{min}^{-1}$ $1.73 \mathrm{~m}^{-2}$ ), and normal urinary albumin levels $(81.5 / 18.5 \%$ with normo-/microalbuminuria). The primary outcome measurement was the rate of change in GFR determined by regression analysis with GFR as a function of time. Patients were followed up for a mean observation period of $5.0 \pm 0.9$ (range: 2.5 to 6.2) years. Results: Univariate and multiple regression analyses yielded a significant association between the rate of change in GFR and baseline haemoglobin concentration. After adjusting for covariates, the rate of decline in GFR was significantly
\end{abstract}

T. Babazono $(\bowtie) \cdot$ K. Hanai $\cdot$ K. Suzuki $\cdot$ Y. Kiuchi $\cdot$ A. Inoue $\cdot$ M. Tanaka $\cdot$ N. Tanaka $\cdot$ M. Hase $\cdot$ A. Ishii

Division of Nephrology and Hypertension, Diabetes Centre, Tokyo Women's Medical University School of Medicine,

8-1 Kawadacho, Shinjukuku,

Tokyo 162-8666, Japan

e-mail: babazono@dmc.twmu.ac.jp

Tel.: +81-3-33538111

Fax: $+81-3-33581941$

T. Babazono $\cdot$ K. Hanai $\cdot$ K. Suzuki $\cdot$ Y. Kiuchi · A. Inoue $\cdot$ M. Tanaka $\cdot$ N. Tanaka $\cdot$ M. Hase · A. Ishii - Y. Iwamoto Department of Medicine, Diabetes Centre,

Tokyo Women's Medical University School of Medicine, Tokyo, Japan greater in patients in the lowest haemoglobin quartile $\left(-3.27 \mathrm{ml} \mathrm{min}^{-1} 1.73 \mathrm{~m}^{-2}\right.$ year $\left.^{-1}\right)$ than in the third $\left(-2.71 \mathrm{ml} \mathrm{min}^{-1} 1.73 \mathrm{~m}^{-2}\right.$ year $\left.^{-1}, p=0.024\right)$ and highest quartiles $\left(-2.78 \mathrm{ml} \mathrm{m^{-1 }} 1.73 \mathrm{~m}^{-2}\right.$ year $\left.^{-1}, p=0.046\right)$. Conclusions/interpretation: Lower haemoglobin concentrations in type 2 diabetic patients without clinical albuminuria may be a significant predictor of subsequent decline in GFR.

Keywords Anaemia - Diabetic nephropathy ·

GFR $\cdot$ Haemoglobin

Abbreviations ACR: albumin:creatinine ratio - ADA: American Diabetes Association - ANCOVA: analysis of covariance $\cdot$ LV: left ventricular - MDRD: Modification of Diet in Renal Disease

\section{Introduction}

In chronic kidney diseases, anaemia commonly results from reduced erythropoietin production of failing kidneys; similarly, in diabetic patients, anaemia is probably associated with erythropoietin deficiency due to concomitant kidney disease $[1,2]$. However, the precise mechanisms of anaemia in diabetic patients are unknown, and a decline in haemoglobin concentrations appears to occur earlier in diabetic patients with nephropathy than in patients with non-diabetic kidney diseases [2-7]. In addition to erythropoietin deficiency due to tubulointerstitial changes, which is an early morphological alteration of diabetic nephropathy [8], autonomic neuropathy [9, 10] and increased serum advanced glycation end-products [11] may participate in the pathogenesis of anaemia in diabetic kidney disease.

Recent studies suggest that anaemia may be an independent risk factor for cardiovascular morbidity and mortality in persons with or without diabetes $[12,13]$. In addition, we [14] and others [15-17] have demonstrated that decreased haematocrit or haemoglobin levels may be useful in identifying type 2 diabetic individuals at 
increased risk of progression of kidney disease. These studies have included diabetic patients with advanced stages of nephropathy, defined as an elevated serum creatinine concentration and/or clinical albuminuria; however, the relationship between haemoglobin levels and the progression of kidney disease in diabetic patients without clinical albuminuria is unknown. We therefore conducted a prospective hospital-based cohort study to examine the relationship between baseline haemoglobin concentrations and the rate of decline in GFR in type 2 diabetic patients with normo- and microalbuminuria.

\section{Subjects and methods}

\section{Study population}

This was an observational prospective cohort study consisting of consecutive patients referred to the outpatient clinic of the Department of Medicine, Diabetes Centre, Tokyo Women's Medical University Hospital in Tokyo, Japan during 1999. At the first visit, medical history was taken, and demographic, anthropometric, and routine laboratory data were collected. Patients were instructed to bring a first-morning urine specimen to the clinic for the determination of albuminuria. Routine laboratory data were regularly monitored during the follow-up visits.

The study included Japanese individuals with type 2 diabetes, aged 20 years or older, with a baseline serum creatinine concentration $<177 \mu \mathrm{mol} / 1 \quad(2.0 \mathrm{mg} / \mathrm{dl})$ and urinary albumin:creatinine ratio (ACR) in the first-morning urine $<300 \mathrm{mg} / \mathrm{g}$ creatinine, indicating normo- or microalbuminuria according to the American Diabetes Association (ADA) criteria [18]. Subjects were excluded from the study if they had been treated with recombinant human erythropoietin or if they had fewer than 2.5 years of followup observation since the first visit. This minimum observation period was selected on the basis of a previous recommendation for an observation period of at least 2 years for valid determination of the rate of decline in GFR [19].

The study protocol was designed in adherence to the Declaration of Helsinki and informed consent was obtained from the subjects.

\section{Methods}

Blood pressure was measured at each visit while the subject was seated, using an oscillometric device (HEM-707; Omron, Kyoto, Japan). Baseline systolic and diastolic blood pressures were defined using average values measured on at least three and up to five visits. Serum creatinine was initially measured by Jaffe's method in the hospital laboratory. From January 2003, the method was replaced by an enzymatic method; therefore, serum creatinine concentrations obtained after January 2003 were adjusted using the following regression equation, obtained from a correlational analysis between both measurements of serum creatinine analysis in 7,370 samples from diabetic patients: serum creatinine (Jaffe's method in $\mu \mathrm{mol} / 1)=1.029 \times$ serum creatinine (enzymatic method in $\mu \mathrm{mol} / \mathrm{l})+20.292(r=0.999, p<0.001)$. Urinary ACR was calculated from urinary albumin, determined using the latex agglutination method, and urinary creatinine concentration, the latter being initially determined using Jaffe's method (until January 2003) and thereafter by an enzymatic method. As the difference between the methods of measuring urine creatinine concentrations was considered negligible, urine creatinine concentrations were not adjusted.

The primary outcome measurement of this study was the rate of change in estimated GFR. GFR was estimated using the following equation, originating from the Modification of Diet in Renal Disease (MDRD) Study group [20], and refitted for Japanese individuals, as recently proposed by the Working Group of Japan Chronic Kidney Disease Initiative: GFR $=186 \times \mathrm{SCr}^{-1.154} \times \mathrm{Age}^{-0.203} \times 0.742$ (if female) $\times 0.881$, where $\mathrm{SCr}=$ serum creatinine (unpublished). In a preliminary assessment of 9,312 Japanese diabetic individuals with serum creatinine $<177 \mu \mathrm{mol} / 1$ and urinary ACR $<300 \mathrm{mg} / \mathrm{g}$ creatinine, estimated GFR values using this equation were well-correlated with values obtained using a quadratic GFR equation [21] $(r=0.865, p<0.001$, Babazono et al., unpublished observations).

For each individual, the rate of change in GFR was determined by the parameter estimates using a simple regression analysis, with GFR as a function of time in years, applied to all estimates of GFRs obtained for that individual during the follow-up period. Because of considerable sex-related differences in haemoglobin concentrations, separate subgroup analyses were also conducted for women and men.

\section{Statistical analysis}

Data are expressed as arithmetic mean $\pm \mathrm{SD}$, geometric mean and $95 \% \mathrm{CI}$, or median and interquartile range, as appropriate according to the data distribution. Continuous data between women and men were compared using Student's $t$-test or Wilcoxon's sum-rank test; categorical data were analysed with Fisher's exact probability test.

To test the effects of haemoglobin levels on the changes in GFR, univariate and multivariate regression analyses were performed. For univariate correlation analyses, Pearson's $(r)$ and Spearman's $(r s)$ correlation coefficients were calculated. For multiple regression analysis, the following were included as covariates: age, diabetes duration, medications for diabetes and hypertension, $\mathrm{BMI}$, systolic and diastolic pressures, $\mathrm{HbA}_{1 \mathrm{C}}$, logarithmically transformed urinary ACR, and estimated GFR at baseline. Diabetes duration was dichotomised at the median. To determine the potent factors associated with the rate of change in estimated GFR, a stepwise selection procedure was performed, specifying the significance levels, both for entering another covariate into the model, and for removing a covariate from the model, as 0.05 . 
Haemoglobin concentration was initially and always included in the model, regardless of whether it reached the significant level.

The rate of change in GFR was also compared among quartiles established using baseline haemoglobin concentrations, after adjusting for covariates by analysis of covariance (ANCOVA). Because of the differences in haemoglobin concentrations between the sexes, separate quartiles were obtained for women and men, and then the quartiles for both sexes were pooled.

All statistical analyses were performed using the Statistical Analysis System (SAS Institute, Cary, NC, USA) version 9.13. A $p$ value of less than 0.05 was considered significant.

\section{Results}

Demographic and clinical characteristics

Among adult individuals with type 2 diabetes who were referred to the outpatient clinic of the Department of Medicine, Diabetes Centre, Tokyo Women's Medical University Hospital in 1999, a total of 564 had sufficient baseline and follow-up data to qualify for inclusion in this study. Of these, 100 patients were excluded due to a serum creatinine level $\geq 177 \mu \mathrm{mol} / \mathrm{l}$ and/or urinary $\mathrm{ACR} \geq 300 \mathrm{mg} / \mathrm{g}$ creatinine. After these exclusions, 464 individuals, including 149 women and 315 men, aged 20 to $85(55 \pm 13$ [mean \pm SD]) years were selected for analysis.

Demographic and clinical characteristics of the subjects included in this study are presented in Table 1. Men had lower systolic and diastolic blood pressure, lower incidence of hypertension, and higher levels of serum creatinine and haemoglobin than women. Estimated GFR and urinary ACR were comparable between the sexes. The presence of anaemia, defined as a haemoglobin concentration $<120 \mathrm{~g} / \mathrm{l}$ in women and $<130 \mathrm{~g} / \mathrm{l}$ in men (a sex-specific definition established by the WHO [22]), was observed in $19(12.8 \%)$ women and $32(10.2 \%)$ men. Using the sexand age-specific anaemia criteria in Japanese adults proposed by the Japanese Society for Dialysis Therapy Guidelines [23], only $6(4.0 \%)$ women and $12(3.8 \%)$ men were diagnosed as having anaemia. Based on ADAguideline criteria [18], $126(84.6 \%)$ women and 252 $(80.0 \%)$ men were classified as having normoalbuminuria, and $23(15.4 \%)$ women and $63(20.0 \%)$ men were classified as having microalbuminuria; 26 (17.4\%)

Table 1 Clinical characteristics of study subjects

\begin{tabular}{|c|c|c|c|}
\hline & Overall $(N=464)$ & Women $(N=149)$ & Men $(N=315)$ \\
\hline Age (years) & $56 \pm 13$ & $56 \pm 14$ & $55 \pm 13$ \\
\hline Known diabetes duration (years) ${ }^{\mathrm{a}}$ & $2.9(0.3-9.5)$ & $2.7(0.3-8.0)$ & $3.0(0.3-9.8)$ \\
\hline BMI $\left(\mathrm{kg} / \mathrm{m}^{2}\right)$ & $24.2 \pm 4.1$ & $24.1 \pm 4.3$ & $24.2 \pm 4.0$ \\
\hline SBP $(\mathrm{mmHg})$ & $135 \pm 19$ & $140 \pm 22$ & $133 \pm 18^{*}$ \\
\hline DBP (mmHg) & $81 \pm 10$ & $82 \pm 11$ & $80 \pm 10^{*}$ \\
\hline \multicolumn{4}{|l|}{ Antihypertensive medications (\%) } \\
\hline ACEI and/or ARB & 8.9 & 10.8 & 8.0 \\
\hline $\mathrm{CCB}$ & 18.7 & 20.3 & 17.9 \\
\hline Others & 7.8 & 8.1 & 7.7 \\
\hline Any & 14.5 & 27.7 & 23.0 \\
\hline Hypertension $(\%)^{\mathrm{c}}$ & 50.9 & 58.4 & $47.3^{*}$ \\
\hline \multicolumn{4}{|l|}{ Antidiabetic medications (\%) } \\
\hline Diet alone & 52.6 & 49.0 & 54.3 \\
\hline Oral hypoglycaemic agents & 35.3 & 38.9 & 33.7 \\
\hline Insulin & 12.1 & 12.1 & 12.0 \\
\hline $\mathrm{HbA}_{1 \mathrm{C}}(\%)$ & $8.4 \pm 2.0$ & $8.3 \pm 1.8$ & $8.4 \pm 2.1$ \\
\hline Haemoglobin (g/l) & $144 \pm 15$ & $135 \pm 14$ & $148 \pm 14^{*}$ \\
\hline Anaemia $(\%)^{\mathrm{d}}$ & 3.9 & 4.0 & 3.8 \\
\hline Serum creatinine $(\mu \mathrm{mol} / \mathrm{l})$ & $82.2 \pm 15.9$ & $69.8 \pm 12.4$ & $88.4 \pm 14.1^{*}$ \\
\hline Estimated GFR $\left(\mathrm{ml} \mathrm{min} \min ^{-1} 1.73 \mathrm{~m}^{-2}\right)$ & $74.8 \pm 14.5$ & $73.6 \pm 14.0$ & $75.4 \pm 14.7$ \\
\hline CKD Stage $1 / 2 / 3(\%)^{\mathrm{e}}$ & $14.8 / 70.0 / 15.1$ & $12.8 / 69.8 / 17.5$ & $15.9 / 70.2 / 14.0$ \\
\hline Urine ACR (mg/g creatinine) ${ }^{\mathrm{b}}$ & $11.5(10.5-12.8)$ & $11.2(9.4-13.3)$ & $11.6(10.2-13.3)$ \\
\hline Normo-/microalbuminuria (\%) & $81.5 / 18.5$ & $84.6 / 15.4$ & $80.0 / 20.0$ \\
\hline
\end{tabular}

Data are expressed as mean $\pm \mathrm{SD}$, percent of patients, ${ }^{\mathrm{a}}$ median (interquartile range), and ${ }^{\mathrm{b}}$ geometric mean (95\% confidence interval) $S B P$ Systolic blood pressure, $D B P$ diastolic blood pressure, $A C E I$ ACE inhibitor, $A R B$ angiotensin receptor antagonist, $C C B$ calcium channel blocker, $C K D$ chronic kidney disease, $A C R$ albumin:creatinine ratio

${ }^{\mathrm{c}} \mathrm{SBP} \geq 140 \mathrm{mmHg}$ and/or DBP $\geq 90 \mathrm{mmHg}$ or treated with antihypertensive medications

defined by the Japanese Society for Dialysis therapy Guideline

${ }^{\text {e Stage 1: GFR } \geq 90 \mathrm{ml} \mathrm{min}}{ }^{-1} 1.73 \mathrm{~m}^{-2}$; stage 2: GFR=60-89 $\mathrm{ml} \mathrm{min}^{-1} 1.73 \mathrm{~m}^{-2}$; stage 3: GFR=30-59 $\mathrm{ml} \mathrm{min}^{-1} 1.73 \mathrm{~m}^{-2}$

$* p<0.05$ vs women 
Table 2 Univariate correlation analysis with changes in GFR as a dependent variable

\begin{tabular}{|c|c|c|c|c|c|c|}
\hline & \multicolumn{2}{|c|}{ Overall $(N=464)$} & \multicolumn{2}{|c|}{ Women $(N=149)$} & \multicolumn{2}{|c|}{$\operatorname{Men}(N=315)$} \\
\hline & $r(r s)$ & $p$ value & $r(r s)$ & $p$ value & $r(r s)$ & $p$ value \\
\hline Age (years) & 0.099 & 0.033 & 0.193 & 0.018 & 0.057 & 0.315 \\
\hline Known diabetes duration (years)* & -0.081 & 0.082 & -0.083 & 0.315 & -0.090 & 0.112 \\
\hline BMI $\left(\mathrm{kg} / \mathrm{m}^{2}\right)$ & 0.151 & 0.001 & 0.035 & 0.676 & 0.204 & $<0.001$ \\
\hline $\mathrm{SBP}(\mathrm{mmHg})$ & 0.012 & 0.803 & -0.059 & 0.473 & 0.074 & 0.190 \\
\hline DBP (mmHg) & 0.112 & 0.016 & 0.101 & 0.220 & 0.127 & 0.024 \\
\hline $\mathrm{HbA}_{1 \mathrm{C}}(\%)$ & -0.083 & 0.077 & -0.086 & 0.296 & -0.086 & 0.129 \\
\hline Serum creatinine $(\mu \mathrm{mol} / \mathrm{l})$ & 0.372 & $<0.001$ & 0.403 & $<0.001$ & 0.380 & $<0.001$ \\
\hline Estimated GFR $\left(\mathrm{ml} \mathrm{min} \min ^{-1} 1.73 \mathrm{~m}^{-2}\right)$ & -0.409 & $<0.001$ & -0.460 & $<0.001$ & -0.399 & $<0.001$ \\
\hline $\mathrm{ACR}(\mathrm{mg} / \mathrm{g} \text { creatinine })^{\mathrm{a}}$ & -0.264 & $<0.001$ & -0.250 & 0.002 & -0.274 & $<0.001$ \\
\hline Haemoglobin (g/l) & 0.152 & 0.001 & 0.111 & 0.177 & 0.134 & 0.017 \\
\hline
\end{tabular}

${ }^{a}$ Because of skewed distribution Spearman's correlation coefficient $(r s)$ was calculated. In other variables, Pearson's coefficient $(r)$ was calculated

SBP Systolic blood pressure, $D B P$ diastolic blood pressure, $A C R$ albumin:creatinine ratio

women and $44(14.0 \%)$ men had an estimated GFR $<60 \mathrm{ml}$ $\min ^{-1} 1.73 \mathrm{~m}^{-2}$, defined as stage 3 chronic kidney disease, according to Kidney Disease Outcomes Quality Initiative guideline [24].

\section{Follow-up data}

The mean and median observation periods were $5.0 \pm 0.9$ and 5.3 years, respectively, ranging from 2.5 to 6.2 years. The median number of follow-up measurements of serum creatinine concentrations, with valid information for estimation of GFR, was 11 measurements per subject and 2.3 measurements per subject per year. No patients were treated with recombinant human erythropoietin at baseline or during the follow-up period, and no subjects reached end-stage renal disease or required dialysis or kidney transplantation. The mean rate of change in GFR change was $-2.94 \pm 2.12 \mathrm{ml} \mathrm{min}{ }^{-1} 1.73 \mathrm{~m}^{-2}$ year $^{-1}$ for overall subjects, $-3.21 \pm 1.95 \mathrm{ml} \mathrm{min}^{-1} 1.73 \mathrm{~m}^{-2}$ year $^{-1}$ for women,

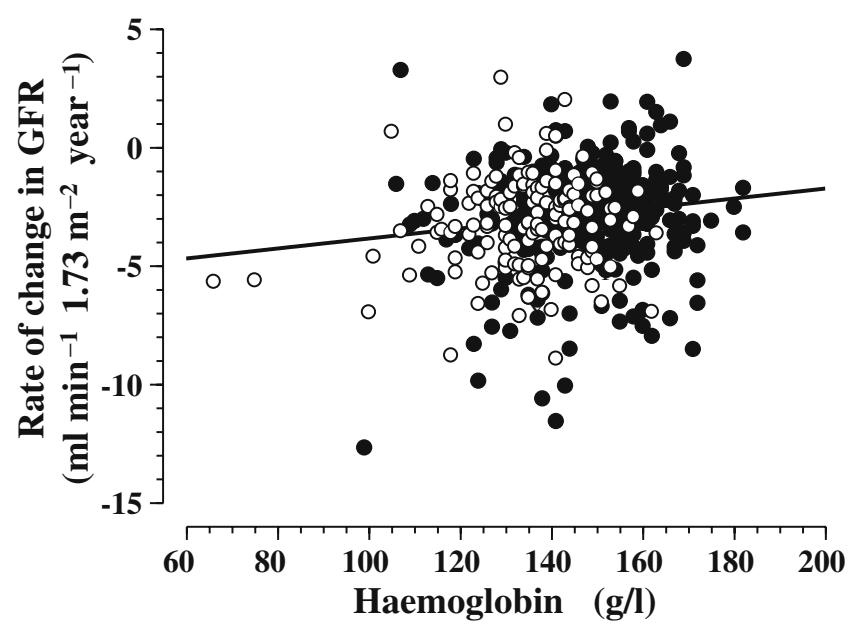

Fig. 1 Correlational analysis between baseline haemoglobin concentration and the rate of change in GFR $(r=0.152, p=0.001)$. Open circles, women; closed circles, men and $-2.81 \pm 2.19 \mathrm{ml} \mathrm{min}{ }^{-1} 1.73 \mathrm{~m}^{-2}$ year $^{-1}$ for men. The difference between the sexes was of marginal statistical significance $(p=0.056)$.

Association between haemoglobin levels and changes in GFR

In the univariate regression analyses, baseline haemoglobin concentration was significantly associated with the rate of change in GFR for study subjects overall $(r=0.152$, $p=0.001$; Table 2, Fig. 1$)$ and in men $(r=0.134, p=0.017)$, but not in women $(r=0.111, p=0.117)$. Baseline urinary ACR and GFR were associated with the rate of change in GFR in both women and men. Based on the correlation coefficients, a lower baseline haemoglobin concentration, higher baseline ACR, and higher baseline GFR were predictive of a faster decline in GFR. Correlations of other variables with the rate of change in GFR are listed in Table 2.

As shown in Table 3, multiple regression analyses demonstrated a significant relationship between haemoglobin concentrations and the rate of change in GFR for all study subjects and, when analysed separately, in men and women. Significant associations of urinary ACR and baseline GFR with the rate of change in GFR were also confirmed in the multiple regression analyses for women and for men (Table 3).

Quartile ranges for baseline haemoglobin concentration for women and men are given in Table 4. Those factors found to be significantly associated with change in GFR in the multiple regression analysis (BMI, logarithmically transformed ACR, and baseline GFR, as well as sex), were incorporated as covariates in the ANCOVA. As shown in Table 4, the rate of change in GFR was significantly greater for the lowest haemoglobin quartile than for the third $(p=0.024)$ and highest quartiles $(p=0.046)$. 
Table 3 Results of multiple regression analyses with stepwise variable selection to determine potent factors associated with changes of estimated GFR per year in patients with type 2 diabetes

\begin{tabular}{|c|c|c|c|c|}
\hline Independent variable & Parameter estimate & Standard error & $p$ value & $\begin{array}{l}\text { Standardised } \\
\text { estimate }\end{array}$ \\
\hline \multicolumn{5}{|l|}{ Overall } \\
\hline Intercept & -2.027 & 0.950 & 0.033 & 0.000 \\
\hline Haemoglobin (g/l) & 0.021 & 0.006 & $<0.001$ & 0.153 \\
\hline BMI $\left(\mathrm{kg} / \mathrm{m}^{2}\right)$ & 0.068 & 0.022 & 0.002 & 0.130 \\
\hline $\log [\mathrm{ACR}(\mathrm{mg} / \mathrm{g} \mathrm{Cr})]$ & -1.094 & 0.170 & $<0.001$ & -0.257 \\
\hline GFR $\left(\mathrm{ml} \mathrm{min} \min ^{-1} 1.73 \mathrm{~m}^{-2}\right)$ & -0.060 & 0.006 & $<0.001$ & -0.403 \\
\hline \multicolumn{5}{|l|}{ Women } \\
\hline Intercept & 0.199 & 1.487 & 0.894 & 0.000 \\
\hline Haemoglobin (g/l) & 0.022 & 0.010 & 0.022 & 0.163 \\
\hline ACEI or ARB (yes/no) & -1.094 & 0.453 & 0.017 & -0.176 \\
\hline $\log [\mathrm{ACR}(\mathrm{mg} / \mathrm{g} \mathrm{Cr})]$ & -0.944 & 0.297 & $<0.001$ & -0.228 \\
\hline GFR $\left(\mathrm{ml} \mathrm{min}-11.73 \mathrm{~m}^{-2}\right)$ & -0.072 & 0.010 & $<0.001$ & -0.506 \\
\hline \multicolumn{5}{|l|}{ Men } \\
\hline Intercept & -2.476 & 1.307 & 0.059 & 0.000 \\
\hline Haemoglobin $(g / l)$ & 0.018 & 0.008 & 0.023 & 0.117 \\
\hline BMI $\left(\mathrm{kg} / \mathrm{m}^{2}\right)$ & 0.093 & 0.028 & $<0.001$ & 0.167 \\
\hline $\log [\mathrm{ACR}(\mathrm{mg} / \mathrm{g} \mathrm{Cr})]$ & -1.080 & 0.210 & $<0.001$ & -0.253 \\
\hline GFR $\left(\mathrm{ml} \mathrm{min}-11.73 \mathrm{~m}^{-2}\right)$ & -0.055 & 0.007 & $<0.001$ & -0.371 \\
\hline
\end{tabular}

$A C R$ Albumin:creatinine ratio

\section{Discussion}

In this hospital-based prospective cohort study in Japanese individuals with type 2 diabetes but without clinical albuminuria, we have demonstrated, for the first time, a significant association between baseline haemoglobin concentrations, most of which were in the normal range, and the rate of decline in GFR. This association was confirmed by treating haemoglobin concentration both continuously in the univariate and multivariate regression analyses and categorically in the ANCOVA. These results are consistent with our earlier observation [14] and other hospital-based cohort studies from Japan [15] and Denmark [17] in diabetic subjects with overt nephropathy, which indicated that decreased haemoglobin concentration or lower haematocrit may be an independent risk factor for the progression of kidney disease in diabetic patients, regardless of the presence of albuminuria. A sub-analysis of the Reduction in Endpoints in NIDDM with the
Angiotensin II Antagonist Losartan study [16] also identified anaemia as a predictor of further progression of advanced kidney disease in patients with type 2 diabetes. The present study therefore extends these findings to diabetic patients with modest renal impairment and normoand microalbuminuria.

In diabetes, anaemia, associated with erythropoietin deficiency, appears to occur earlier in the course of progression of kidney disease than in non-diabetic patients with kidney diseases [2-7]. Haemoglobin concentrations were found to be significantly decreased in patients with microalbuminuria compared to patients with normoalbuminuria [3]. Autonomic neuropathy has been postulated to play a role in erythropoietin dysregulation in diabetic patients $[9,10]$. In addition, nutrient deficiencies including iron, folate, and vitamin $\mathrm{B} 12$, or undetected malignant diseases or anaemia of chronic inflammation (formally termed anaemia of chronic diseases) [25] may contribute to anaemia in diabetic subjects. Although a majority of

Table 4 Comparison of adjusted rate of change in GFR by quartiles based on baseline haemoglobin concentration

\begin{tabular}{|c|c|c|c|c|c|c|}
\hline \multirow[t]{2}{*}{ Quartile } & \multicolumn{2}{|c|}{ Range of haemoglobin (g/l) } & \multicolumn{2}{|c|}{ Number of subjects } & \multirow{2}{*}{$\begin{array}{l}\text { Rate of change in GFR } \\
\left(\mathrm{ml} \mathrm{min}-1.73 \mathrm{~m}^{-2} \text { year }^{-1}\right)^{\mathrm{a}}\end{array}$} & \multirow[t]{2}{*}{$p$ value $^{\mathrm{b}}$} \\
\hline & Women & Men & Women & Men & & \\
\hline First & $<126$ & $<141$ & 38 & 82 & $-3.27 \pm 0.17$ & - \\
\hline Second & $129-135$ & $141-149$ & 35 & 78 & $-2.99 \pm 0.17$ & 0.251 \\
\hline Third & $136-143$ & $150-157$ & 38 & 77 & $-2.71 \pm 0.17$ & 0.024 \\
\hline Fourth & $\geq 144$ & $\geq 158$ & 38 & 78 & $-2.78 \pm 0.17$ & 0.046 \\
\hline
\end{tabular}

Haemoglobin quartiles were determined separately for women and men, and then pooled

${ }^{a}$ Adjusted mean $( \pm$ SEM) for BMI, logarithmically transformed ACR, baseline GFR, and sex

${ }^{\mathrm{b}}$ versus the first quartile 
diabetic patients in our study were normoalbuminuric and not overtly anaemic, our data suggest lower haemoglobin levels predict a more rapid rate of decline in GFR. However, the difference in the rate of decline in GFR between the lowest and highest haemoglobin concentration quartile $\left(-3.27 \pm 0.17\right.$ vs $-2.78 \pm 0.17 \mathrm{ml} \mathrm{min}^{-1} 1.73 \mathrm{~m}^{-2}$ year $^{-1}, p=0.046$ ) was relatively modest for patients in this study.

The mechanisms by which lower haemoglobin levels may impact on the progression of chronic kidney disease in type 2 diabetes are unknown. Some of the explanations may be provided by in vitro and in vivo studies examining the effects of anaemia-induced renal hypoxia and oxidative stress. In culture cells, hypoxia has been found to increase mesangial/tubular cell extracellular matrix synthesis, leading to fibrogenic changes in the kidney by activating several gene transcripts including transforming growth factor- $\beta$ (TGF- $\beta$ ), osteopontin, and the recently discovered hypoxia inducing factor-1 (HIF-1) [26, 27]. Hypoxiainduced altered renal sympathetic nerve activity may differentially regulate glomerular haemodynamics [28]. Close associations between anaemia and cardiac disorders, including left ventricular (LV) hypertrophy and heart failure [29, 30], may also provide a basis for explaining the anaemia-induced loss of kidney function in diabetes, as these conditions are associated with decreased effective renal blood flow. Indeed, an increase in LV mass has been reported to occur early in the course of diabetic nephropathy. However, no significant association was observed between haemoglobin concentrations and LV mass index [31] in type 1 diabetic patients with nephropathy.

Several retrospective trials have suggested that correction of anaemia with erythropoietin may delay the onset of dialysis in predialysis patients [32, 33]; however, the benefits of treating anaemia associated with early diabetic nephropathy are still uncertain. This observational study did not attempt to determine whether correction of anaemia in early stages of diabetic kidney disease attenuates the decline rate of kidney function. Ongoing prospective multicentre studies such as the Anaemia Correction in Diabetes trial [34] and Effect of early Correction of Anaemia on the Progression of Chronic Kidney Disease (ECAP) trial [35] may provide important information in this regard.

Our study has several limitations. It was carried out in an urban university hospital in an ethnically homogenous population, which may not be representative of the entire type 2 diabetic patient population. The generalisability of these findings will need to be confirmed in future studies. The original and refitted MDRD equations may have limitations for estimating GFR in individuals with normal or near-normal kidney function [36, 37]. Our preliminary observations suggest that estimated GFR using the refitted MDRD equation in Japanese diabetic patients is well correlated with values obtained using a quadratic GFR equation, which is reported to perform better than the MDRD equation in healthy individuals [21]. Although the performance of creatinine-based estimation of GFR remains at issue, the disputed factors would affect absolute values most, and are of less importance when assessing individual change in GFR over a long period, which was the main focus of the present study. Finally, urinary ACR was measured on a single occasion, possibly leading to overestimation of albuminuria because of marked day-today variability in albumin excretion [38]. The ADA guideline recommends repeating measurements of urinary albumin for the classification of abnormalities in albumin excretion [18]. Although we did not obtain multiple measurements of urinary ACR, we restricted the timing of urine collection to first morning urine to minimise the variation of albumin excretion due to exercise and diurnal fluctuations [38, 39].

In conclusion, this hospital-based prospective cohort study in Japanese patients with type 2 diabetes indicates that lower haemoglobin concentration may be a significant predictor of subsequent decline in GFR even in patients without clinical albuminuria. Results of ongoing trials on the effect of correcting anaemia on the progression of early stages of diabetic kidney disease are eagerly awaited.

\section{References}

1. Winkler AS, Marsden J, Chaudhuri KR, Hambley H, Watkins PJ (1999) Erythropoietin depletion and anemia in diabetes mellitus. Diabet Med 16:813-819

2. Bosman DR, Winkler AS, Marsden JT, Macdougall IC, Watkins PJ (2001) Anemia with erythropoietin deficiency occurs early in diabetic nephropathy. Diabetes Care 24:495-499

3. Thomas MC, MacIsaac RJ, Tsalamandris C, Power D, Jerums G (2003) Unrecognized anemia in patients with diabetes: a cross-sectional survey. Diabetes Care 26:1164-1169

4. Thomas MC, MacIsaac RJ, Tsalamandris C et al (2004) Anemia in patients with type 1 diabetes. J Clin Endocrinol Metab 89:4359-4363

5. El-Achkar TM, Ohmit SE, McCullough PA et al (2005) Higher prevalence of anemia with diabetes mellitus in moderate kidney insufficiency: The Kidney Early Evaluation Program. Kidney Int 64:1483-1488

6. Thomas MC, Cooper ME, Tsalamandris C, MacIsaac R, Jerums $\mathrm{G}$ (2005) Anemia with impaired erythropoietin response in diabetic patients. Arch Intern Med 165:466-469

7. Craig KJ, Williams JD, Riley SG et al (2005) Anemia and diabetes in the absence of nephropathy. Diabetes Care 28:1118-1123

8. Nath KA (1992) Tubulointerstitial changes as a major determinant in the progression of renal damage. Am J Kidney Dis 20:1-17

9. Spallone V, Maiello MR, Kurukulasuriya N et al (2004) Does autonomic neuropathy play a role in erythropoietin regulation in non-proteinuric Type 2 diabetic patients? Diabet Med 21:1174-1180

10. Bosman DR, Osborne CA, Marsden JT, Macdougall IC, Gardner WN, Watkins PJ (2002) Erythropoietin response to hypoxia in patients with diabetic autonomic neuropathy and non-diabetic chronic renal failure. Diabet Med 19:65-69

11. Thomas MC, Tsalamandris C, MacIsaac R et al (2004) Lowmolecular-weight AGEs are associated with GFR and anemia in patients with type 2 diabetes. Kidney Int 66:1167-1172

12. Horwich TB, Fonarow GC, Hamilton MA, MacLellan WR, Borenstein J (2002) Anemia is associated with worse symptoms, greater impairment in functional capacity and a significant increase in mortality in patients with advanced heart failure. J Am Coll Cardiol 39:1780-1786 
13. Al-Ahmad A, Rand WM, Manjunath G et al (2001) Reduced kidney function and anemia as risk factors for mortality in patients with left ventricular dysfunction. J Am Coll Cardiol 38:955-962

14. Yokoyama H, Tomonaga O, Hirayama $M$ et al (1997) Predictors of the progression of diabetic nephropathy and the beneficial effect of angiotensin-converting enzyme inhibitors in NIDDM patients. Diabetologia 40:405-411

15. Ueda H, Ishimura E, Shoji $T$ et al (2003) Factors affecting progression of renal failure in patients with type 2 diabetes. Diabetes Care 26:1530-1534

16. Mohanram A, Zhang Z, Shahinfar S, Keane WF, Brenner BM, Toto RD (2004) Anemia and end-stage renal disease in patients with type 2 diabetes and nephropathy. Kidney Int 66:1131-1138

17. Rossing K, Christensen PK, Hovind P, Tarnow L, Rossing P, Parving HH (2004) Progression of nephropathy in type 2 diabetic patients. Kidney Int 66:1596-1605

18. American Diabetes Association (2004) Nephropathy in diabetes. Diabetes Care 27(Suppl1):S79-S83

19. Levey AS, Gassman JJ, Hall PM, Walker WG (1991) Assessing the progression of renal disease in clinical studies: effects of duration of follow-up and regression to the mean. Modification of Diet in Renal Disease (MDRD) Study Group. J Am Soc Nephrol 1:1087-1094

20. Levey AS, Bosch JP, Lewis JB, Greene T, Rogers N, Roth D (1999) A more accurate method to estimate glomerular filtration rate from serum creatinine: a new prediction equation. Ann Intern Med 130:461-470

21. Rule AD, Larson TS, Bergstralh EJ, Slezak JM, Jacobsen SJ, Cosio FG (2004) Using serum creatinine to estimate glomerular filtration rate: accuracy in good health and in chronic kidney disease. Ann Intern Med 141:929-937

22. World Health Organization (1968) Nutritional Anemia: Report of a WHO Scientific Group. World Health Organization, Geneva

23. Gejyo F, Saito A, Akizawa T et al (2004) Japanese Society for Dialysis therapy guidelines for renal anemia in chronic hemodialysis patients. Ther Apher Dial 8:443-459

24. Levey AS, Coresh J, Balk E et al (2003) National Kidney Foundation practice guidelines for chronic kidney disease: evaluation, classification, and stratification. Ann Intern Med 139:137-147

25. Guralnik JM, Eisenstaedt RS, Ferrucci L, Klein HG, Woodman RC (2004) Prevalence of anemia in persons 65 years and older in the United States: evidence for a high rate of unexplained anemia. Blood 104:2263-2268

26. Sahai A, Mei C, Schrier RW, Tannen RL (1999) Mechanisms of chronic hypoxia-induced renal cell growth. Kidney Int $56: 1277-1281$
27. Norman JT, Clark IM, Garcia PL (2000) Hypoxia promotes fibrogenesis in human renal fibroblasts. Kidney Int 58:2351-2366

28. Denton KM, Shweta A, Anderson WP (2002) Preglomerular and postglomerular resistance responses to different levels of sympathetic activation by hypoxia. J Am Soc Nephrol 13:27-34

29. McClellan WM, Flanders WD, Langston RD, Jurkovitz C, Presley R (2002) Anemia and renal insufficiency are independent risk factors for death among patients with congestive heart failure admitted to community hospitals: a population-based study. J Am Soc Nephrol 13:1928-1936

30. Weiner DE, Tighiouart H, Vlagopoulos PT et al (2005) Effects of anemia and left ventricular hypertrophy on cardiovascular disease in patients with chronic kidney disease. J Am Soc Nephrol 16:1803-1810

31. Sato A, Tarnow L, Parving HH (1999) Prevalence of left ventricular hypertrophy in Type I diabetic patients with diabetic nephropathy. Diabetologia 42:76-80

32. Kuriyama S, Tomonari H, Yoshida H, Hashimoto T, Kawaguchi Y, Sakai O (1997) Reversal of anemia by erythropoietin therapy retards the progression of chronic renal failure, especially in nondiabetic patients. Nephron 77:176-185

33. Jungers P, Choukroun G, Oualim Z, Robino C, Nguyen AT, Man NK (2001) Beneficial influence of recombinant human erythropoietin therapy on the rate of progression of chronic renal failure in predialysis patients. Nephrol Dial Transplant $16: 307-312$

34. Laville M (2004) Anaemia CORrection in Diabetes trial: new strategies in anaemia management: ACORD (Anaemia CORrection in Diabetes) trial. Acta Diabetol 41(Suppl 1):S18-S22

35. Deicher R, Horl WH (2003) Anemia as a risk factor for the progression of chronic kidney disease. Curr Opin Nephrol Hypertens 12:139-143

36. Lin J, Knight EL, Hogan ML, Singh AK (2003) A comparison of prediction equations for estimating glomerular filtration rate in adults without kidney disease. J Am Soc Nephrol 14:2573-2580

37. Poggio ED, Wang X, Greene T, Van Lente F, Hall PM (2005) Performance of the modification of diet in renal disease and Cockcroft-Gault equations in the estimation of GFR in health and in chronic kidney disease. J Am Soc Nephrol 16:459-466

38. Howey JE, Browning MC, Fraser CG (1987) Selecting the optimum specimen for assessing slight albuminuria, and a strategy for clinical investigation: novel uses of data on biological variation. Clin Chem 33:2034-2038

39. Babazono T, Takahashi C, Iwamoto Y (2004) Definition of microalbuminuria in first-morning and random spot urine in diabetic patients. Diabetes Care 27:1838-1839 